\title{
O SUPERIOR TRIBUNAL DE JUSTIÇA E A RESERVA DO POSSÍVEL NO DIREITO À SAÚDE ${ }^{1}$
}

\section{THE BRAZILIAN SUPERIOR COURT OF JUSTICE AND THE RESERVE OF THE POSSIBLE IN THE RIGHT TO HEALTH}

\author{
GERMANO SCHWARTZ ${ }^{2}$ \\ RAFAELA LEMOS GUILHERME ${ }^{3}$
}

\begin{abstract}
RESUMO: Este artigo tem por escopo analisar o entendimento da jurisprudência do Superior Tribunal de Justiça (STJ) acerca da aplicação da teoria da reserva do possível no direito à saúde. A partir desse pressuposto, busca-se verificar se a Corte Superior, mediante suas decisões, tem contribuído para a efetivação do referido direito. Para tanto, foram examinadas oitenta decisões proferidas pela segunda turma do STJ. Refira-se que a metodologia utilizada foi a bibliográfica e documental, através da coleta de dados. Importa destacar que das oitenta decisões analisadas, apenas três negaram o direito fundamental à saúde em prol da reserva do possível.

PALAVRAS-CHAVE: Custos dos Direitos; Decisões Judiciais; Direito à Saúde; Direitos Sociais; Reserva do Possível.
\end{abstract}

\begin{abstract}
The present article means to analyze the Superior Court of Justice jurisprudential understanment about the reserve of the possible theory application in health rights. Starting with this proposition, it seeks to verify if the Superior Court, in its decisions, has contributed to the effective use of the referred rights. For that, eighty decisions made by the Superior Court of Justice's second group were examined. It refers to say that the method used was strictly bibliographic and documental and was made by data analysis. It is important to highlight that,
\end{abstract}

\footnotetext{
Comentário de Jurisprudência recebido em 05.11.2012. Comentário de Jurisprudência aceito para publicação em 19.11.2012.

${ }_{1}^{1}$ Os resultados obtidos na primeira fase da pesquisa podem ser vistos no artigo intitulado "O poder judiciário gaúcho e a reserva do possível no direito à saúde" publicado na Revista eletrônica Direito e Política Pública do programa de Pós-Graduação Stricto Sensu em Ciência Jurídica da UNIVALI, Itajaí, v. 5, $\mathrm{n}^{\circ} 2,2^{\circ}$ quadrimestre de 2010, disponível em: www.univali.br/ direitoepolitica. ISSN: 1980-7791.

${ }^{2}$ Pós-Doutor em Direito (Universityof Reading). Doutor em Direito (Unisinos) com estágio doutoral na Université Paris X - Nanterre (Centre de Theorie du Droit). Segundo Vice-Presidente da Associação Brasileira de Pesquisadores em Sociologia do Direito (ABRASD). Secretário do Research Committee on Sociology of Law da International Sociological Association (RCSL-ISA). Professor do Mestrado em Memória Social e Bens Culturais do Unilasalle. Docente dos Cursos de Graduação em Direito da FADERGS e da FSG. germano.schwartz@globo.com

${ }^{3}$ Advogada graduada em Direito pela ULBRA/Canoas. rafa.lemos@yahoo.com.br
} 
of the eighty examined decisions, only three denied the health fundamental, considering the reserve of the possible more important.

KEYWORDS: Cost of Rights; Judgments; Right to Health; Social Rights; Possible Reserve.

SUMÁRIO: 1. Bases para a Análise; 2. Objetivos da Análise; 3. Por que a opção pelo Superior Tribunal de Justiça?; 3.1 Análise dos Dados; Considerações Finais; Referências Bibliográficas.

SUMMARY: 1. Bases for the Analyses; 2 . Aims of the Analyses; 3 . Why the Superior Court of Justice?; 3.1 Analyzes of the Datas; Final Remarks; Bibliographical References.

\section{BASES PARA A ANÁLISE}

A Constituição Federal de 1988 conferiu destaque aos direitos fundamentais, uma vez que já no Título II trata dos direitos e garantias fundamentais antes mesmo da organização do Estado (Título III) ${ }^{4}$. Outrossim, a nossa atual Carta Política discorre acerca dos direitos sociais em seus artigos $6^{\circ}$ a 11. Nesse sentido, salienta-se que o art. $6^{\circ}$ da Lei Maior estabelece que a saúde é um direito social e, mais adiante, no art. 196 dispõe que a saúde é um direito de todos e dever do Estado, que deve garanti-lo mediante políticas sociais e econômicas.

Entretanto, apesar de garantido constitucionalmente, o direito à saúde, no Brasil, ainda não alcançou sua máxima eficácia ${ }^{5}$. Isso porque o referido direito requer prestações materiais por parte do Poder Público ${ }^{6}$ e, portanto, necessita de recursos financeiros para sua efetivação. Não obstante, refira-se que os obstáculos enfrentados pelos direitos sociais não foram impostos aos direitos de defesa ${ }^{7}$. Isso ocorreu porque, no caso dos direitos individuais

\footnotetext{
${ }^{4}$ FERREIRA FILHO, Manoel Gonçalves. Direitos Humanos Fundamentais. 9. ed., rev., São Paulo: Saraiva, 2007. p. 99.

${ }^{5}$ De acordo com os resultados parciais obtidos por uma pesquisa realizada pelo Conselho Nacional de Justiça (CNJ), nos 20 tribunais que já foram analisados, existem 112.324 processos referentes à saúde em aberto. A maior parte dessas demandas consiste em reclamações de pessoas que postulam o fornecimento de medicamentos e acesso a procedimentos médicos pelo Sistema Único de Saúde (SUS), além de vagas em hospitais públicos. (Disponível em: <http://www.cnj.jus.br/index.php?option=com_content\&view=article\&id=12515:demandas-de-saudepassam-de-112-mil-em-todo-o-pais\&catid=1:notas\&ltemid=675> Acesso em: 13 jan. 2011). Nesse sentido, o grande número de demandas judiciais referentes à saúde demonstra a insatisfação da população, tornando evidente que o Brasil ainda encontra dificuldades em promover a efetivação do referido direito.

${ }^{6}$ Conforme estabelece o artigo sexto da Constituição Federal, a saúde é um direito social e, nesse sentido, conforme ensina Cristina Queiroz, reporta-se que os direitos fundamentais sociais são aqueles que "constituem obrigações de prestação positivas cuja satisfação consiste num facere, uma 'acção positiva' a cargo dos poderes públicos." (QUEIROZ, Cristina. Direitos Fundamentais Sociais: funções, âmbito, conteúdo, questões interpretativas e problemas de justiciabilidade. Coimbra: Coimbra Editora, 2006. p. 25. (grifo do autor)).

${ }^{7}$ Giza-se que, assim como os direitos sociais, os direitos de defesa (liberdade propriedade) também possuem custos e, no entanto, tais direitos não tiveram sua efetivação impedida, conforme ensina Sarlet, a efetividade dos direitos negativos "[...] naquilo que depende da sua
} 
bastaria a abstenção do Poder Estatal, enquanto que nos direitos sociais o Estado é obrigado a prestar um atendimento positivo, necessitando, dessa forma, de recursos financeiros ${ }^{8}$. No entanto, para Victor Abramovich, distinguir os direitos individuais dos direitos sociais faz parte de um ideal liberalista que defende um Estado mínimo, cuja função seja apenas garantir justiça, segurança e defesa'.

Dessa forma, com a finalidade de regular sua obrigação constitucional, o Estado passou a utilizar em sua defesa a teoria da reserva do possível. Cumpre reportar que a teoria da reserva do possível surgiu na Alemanha com a famosa decisão "numerus clausus" (BverfGE n 33, S. 333) de vagas nas Universidades. No caso referido, a Corte Constitucional alemã entendeu que existem limitações fáticas para o atendimento de todas as demandas de acesso a um direito. ${ }^{10}$ Logo, depreende-se que a referida teoria consiste na restrição do poder do Estado em concretizar efetivamente direitos fundamentais devido à escassez orçamentária.

Não obstante, Fernando Borges Mânica entende que a teoria da reserva do possível não concerne tão somente à falta de recursos, mas também à "razoabilidade da pretensão deduzida com vistas à sua efetivação" ${ }^{11}$ Compartilhando do entendimento de Mânica, Gustavo Amaral defende que a grande questão não diz respeito à escassez propriamente dita, mas à divisibilidade e à homogeneidade da distribuição dos recursos. Segundo o autor, não se pode garantir tudo a todos e, portanto, a escolha de quais pacientes terão suas necessidades atendidas é estritamente necessária ${ }^{12}$. Nesse sentido, os referidos autores defendem que o direito à saúde não é imune aos critérios de razoabilidade e ponderação.

Outro ponto importante é o que concerne ao princípio da separação dos poderes. O que se questiona é a possibilidade do Poder Judiciário interferir no poder discricionário da Administração Pública, uma vez que é de competência

implementação jurisdicional não têm sido colocada na dependência da sua possível relevância econômica". Já no que diz com os direitos sociais a prestações, seu "custo" assume especial relevância no âmbito da sua eficácia e efetivação [...] (SARLET, Ingo. A Eficácia dos Direitos Fundamentais: uma teoria dos direitos fundamentais na perspectiva constitucional. 10. ed., ver. atual. e ampl. Porto Alegre: Livraria do Advogado Ed., 2009. p. 285).

${ }^{8}$ SARLET, Ingo. A Eficácia dos Direitos Fundamentais: uma teoria dos direitos fundamentais na perspectiva constitucional. p. 285.

9 ABRAMOVICH, Víctor. Linhas de Trabalho em Direitos Econômicos, Sociais e Culturais: instrumentos e aliados. Revista Internacional de Direitos Humanos. Ano 2, no 2, p. 188-223, 2005, Edição em português, Tradução de Maria Lucia de oliveira Marques. p. 190.

${ }^{10}$ MÂNICA, Fernando Borges. Teoria da Reserva do Possível: direitos fundamentais a prestações e a intervenção do Poder Judiciário na implementação de políticas públicas. In: Revista Brasileira de Direito Público. Belo Horizonte, Ano 5, nº 18, p. 169-186, jul./set. 2007. p. 181.

${ }_{11}$ MÂNICA, Fernando Borges. Teoria da Reserva do Possível: direitos fundamentais a prestações e a intervenção do Poder Judiciário na implementação de políticas públicas. In: Revista Brasileira de Direito Público. p. 181.

${ }^{12}$ AMARAL, Gustavo. Direito, Escassez e Escolha: em busca de critérios jurídicos para lidar com a escassez de recursos e as decisões trágicas. Rio de Janeiro: Renovar, 2001. p. 133-137. 
da Administração elaborar listas de medicamentos que serão fornecidos à população ${ }^{13}$. Dessa maneira, quando, por exemplo, o Judiciário condena ${ }^{14} \mathrm{o}$ Estado a entregar um medicamento que não consta nas listas do Sistema Único de Saúde (SUS), estaria interferindo na esfera de competência do Poder Executivo ${ }^{15}$, ferindo, portanto, o princípio da tripartição dos poderes ${ }^{16}$. Igualmente, a licitude da determinação do bloqueio de valores em contas públicas pelo magistrado a fim de garantir o custeio de tratamento médico indispensável, bem como a cominação de multa diária em desfavor da Fazenda Pública em caso de eventual descumprimento de obrigação de fazer são outros assuntos bastante controvertidos na doutrina.

No centro desse debate encontra-se o cidadão cujo único desiderato é a efetivação de um direito seu. Em face disso, a única alternativa que lhe resta é a busca por tutela jurisdicional. Destarte, o levantamento de dados jurisprudenciais é imprescindível a fim de auxiliar na formação de uma posição concreta no direcionamento dos julgados. Ademais, a análise dessas decisões contribui para verificar se o Judiciário tem concorrido para a efetivação do direito à saúde, uma vez que é sua função zelar pela proteção dos direitos ${ }^{17}$.

\footnotetext{
${ }^{13}$ Veja o artigo $6^{\circ}$, VI c/c o artigo $4^{\circ}$ da Lei $n^{\circ} 8.080 / 90$.

${ }^{14}$ Veja como exemplo o Agravo Regimental na Medida Cautelar $n^{\circ} 11.405$ - RJ, disponível em $<$ http://www.stj.jus.br/SCON/>. Esse caso trata acerca do pedido de antecipação de tutela, intentada por José Maria Garcia Perez, portador de deficiência física, com vistas a compelir os réus, dentre eles o município do Rio de Janeiro, a lhe fornecer um esfíncter artificial padrão ANS-800, argumentando constituir-se a saúde um direito de todos e dever do Estado. O município em defesa aduziu que a Lei ${ }^{\circ} 8.080 / 90$ não garante o acesso indiscriminado das pessoas a todo e qualquer tipo de equipamento para tratamento de saúde, ressaltando que a implementação da política pública de saúde é de competência privativa do Poder Executivo, a quem caberia indicar quais os remédios e equipamentos devem ser disponibilizados em seus nosocômios e estabelecimentos de saúde. Contudo, o Ministro Relator João Otávio de Noronha entendeu ser dever do município fornecer o equipamento pleiteado, como demonstra a ementa de seu voto: "1. Esta Corte tem reconhecido que os portadores de moléstias graves, que não tenham disponibilidade financeira para custear o seu tratamento, têm o direito de receber gratuitamente do Estado os medicamentos de comprovada necessidade. Precedentes. 2. O direito à percepção de tais medicamentos decorre de garantias previstas na Constituição Federal, que vela pelo direito à vida (art. $5^{\circ}$, caput) e à saúde (art. $6^{\circ}$ ), competindo à União, Estados, Distrito Federal e Municípios o seu cuidado (art. 23, II), bem como a organização da seguridade social, garantindo a "universalidade da cobertura e do atendimento" (art. 194, parágrafo único, I). 3. A Carta Magna também dispõe que "A saúde é direito de todos e dever do Estado, garantido mediante políticas sociais e econômicas que visem à redução do risco de doença e de outros agravos e ao acesso universal e igualitário às ações e serviços para sua promoção, proteção e recuperação" (art. 196), sendo que o "atendimento integral" é uma diretriz constitucional das ações e serviços públicos de saúde (art. 198). 4. In casu, não havendo prova documental de que o remédio fornecido gratuitamente pela administração pública tenha a mesma aplicação médica que o prescrito ao impetrante - declarado hipossuficiente -, fica evidenciado o seu direito líquido e certo de receber do Estado o remédio pretendido." Salienta-se que o voto do Ministro Relator foi seguindo pelos demais Ministros presentes.

${ }^{15}$ Veja os artigos 23 , Il e 196, caput da CF/88, e o artigo $2^{\circ}$ da Lei $n^{\circ} 8.080 / 90$.

${ }_{17}^{16}$ Veja o artigo $2^{\circ}$ da CF/88.

${ }^{17} \mathrm{O}$ inciso XXXVI do artigo quinto da Constituição Federal atribui ao judiciário a apreciação de lesão ou ameaça de lesão a direito.
} 
De interesse de todos é, por conseguinte, o estudo do entendimento da jurisprudência pátria acerca do tema.

\section{OBJETIVOS DA ANÁLISE}

Como se pode perceber o direito à saúde encontra uma série de obstáculos a sua efetivação. Nesse sentido, cumpre lembrar que a função precípua do Poder Judiciário consiste na tutela dos direitos subjetivos, em especial dos direitos fundamentais, conforme salientam Antônio Carlos de Araújo Cintra, Ada Pellegrini Grinover e Cândido Rangel Dinamarco:

Os direitos fundamentais, formulados pela Constituição através de normas necessariamente vagas e genéricas, quando violados ou postos em dúvida só podem ser firmados, positivados e efetivados pelos tribunais.

$[\ldots]$

É perante o Poder Judiciário, portanto, que se pode efetivar a correção da imperfeita realização automática do direito $[\ldots]^{18}$.

Nesse contexto, este artigo tem por objetivo verificar como o Poder Judiciário tem contribuído na correção da falta de concretização do direito à saúde, mediante o entendimento jurisprudencial acerca do argumento da escassez de recursos na saúde. Necessário referir, outrossim, que, num primeiro momento, foram analisadas a jurisprudência do Tribunal de Justiça do Rio Grande do Sul - TJRS ${ }^{19}$ - e, posteriormente, do Tribunal Regional Federal da Quarta Região - TRF4. Salienta-se que, após a coleta e análise dos dados encontrados nos julgados desses tribunais, passou-se ao exame da jurisprudência do Superior Tribunal de Justiça - STJ.

Frisa-se que as decisões escolhidas foram julgadas no período entre 2002 e 2010 e coletadas no site do Superior Tribunal de Justiça (http://www.stj.jus.br/SCON/). Ademais, os julgados foram selecionados mediante pesquisa dos termos "medicamentos $E$ saúde $E$ fornecimento" Em seguida, procedeu-se a leitura das decisões a fim de se verificar quais delas tratavam acerca da teoria da reserva do possível na saúde. Destaca-se que, após essa seleção, foram separados oitenta julgados para análise dos

\footnotetext{
${ }^{18}$ CINTRA, Antônio Carlos de Araújo; GRINOVER, Ada Pellegrini; DINAMARCO, Cândido Rangel. Teoria Geral do Processo. 22. ed., rev. e atual., São Paulo: Malheiros Editores, 2006. p. 172.

19 As decisões examinadas foram prolatadas pela Primeira Câmara e pela Sétima Câmaras Cíveis do Tribunal de Justiça do Rio Grande do Sul. Refira-se que das 100 decisões proferidas pela Primeira Câmara Cível, nenhuma acolheu a tese da reserva do possível no direito à saúde, enquanto que, dos 41 julgados proferidos pela Sétima Câmara, apenas 17 entenderam que o direito à saúde se sobrepõe a referida teoria. Para maiores detalhes, veja o artigo "O Poder Judiciário gaúcho e a reserva do possível no direito à saúde" publicado na Revista Eletrônica Direito e Política do Programa de Pós-Graduação Stricto Sensu em Ciência Jurídica da Itajaí, v. 5, $n^{\circ} 2,2^{\circ}$ quadrimestre de 2010, disponível em: www.univali.br/direitoepolitica ISSN: 1980-7791.

${ }^{20}$ Nesse sentido, merece destaque que os termos utilizados na pesquisa foram escolhidos devido ao fato de que a grande maioria das demandas que dizem respeito ao direito à saúde consiste em pedidos de medicamentos.
} 
argumentos utilizados pelos Ministros a fim de acolher ou rejeitar a teoria da escassez dos recursos na saúde. Além disso, merece destaque que as decisões examinadas foram julgadas pela Segunda Turma da Primeira Seção da Corte Especial devido a sua competência para julgar casos referentes à saúde, conforme estabelece o Regimento Interno do Superior Tribunal de Justiça $^{21}$.

\section{POR QUE A OPÇÃO PELO SUPERIOR TRIBUNAL DE JUSTIÇA?}

Inicialmente, importa referir que a presente análise faz parte de um projeto maior que visa analisar como o Poder Judiciário tem contribuído para a efetivação do direito à saúde no Brasil. Igualmente destaca-se que, na primeira fase dessa pesquisa, foi examinada a jurisprudência do Tribunal de Justiça do Rio Grande do Sul e, em um segundo momento, a jurisprudência do Tribunal Regional Federal da Quarta Região ${ }^{22}$. Com o intuito de dar andamento ao projeto, partiu-se para a análise das decisões proferidas pelos Tribunais Superiores brasileiros, iniciando-se pelo Superior Tribunal de Justiça.

Ressalta-se que o direito à saúde, no Brasil, tem enfrentado uma série de obstáculos à sua efetivação e, desse modo, o cidadão se vê obrigado a buscar tutela jurisdicional. Prova disso é o que um estudo que está sendo realizado pelo Conselho Nacional de Justiça - $\mathrm{CNJ}$-, desde o a no passado, pelo Fórum Nacional do Judiciário para a Saúde - nos Tribunais de Justiça e Tribunais Regionais das cinco regiões - constatou que tramitam hoje, no Judiciário brasileiro, 240.980 processos judiciais na área da saúde. Uma grande parcela dessas demandas refere-se a reclamações de pessoas que pleiteiam na Justiça o fornecimento de medicamentos e procedimentos médicos pelo Sistema Único de Saúde - SUS -, bem como vagas em hospitais públicos. A respeito dessas demandas supramencionadas deve-se levar em conta que o Sistema Único de Saúde elevou o número de pessoas inseridas na proteção estatal da saúde. Outrora 30 milhões, agora são 190 milhões ${ }^{23}$.

A pesquisa, que está em andamento, já demonstra que as piores situações estão no Rio Grande do Sul, em São Paulo e no Rio de Janeiro.

\footnotetext{
${ }^{21}$ Art. $9^{\circ}$ A competência das Seções e das respectivas Turmas é fixada em função da natureza da relação jurídica litigiosa. § $1^{\circ}$ À Primeira Seção cabe processar e julgar os feitos relativos a: XIII - direito público em geral, exceto benefícios previdenciários.

${ }^{22}$ Foram analisadas 94 decisões proferidas pela $3^{\mathrm{a}}$ e $4^{\mathrm{a}}$ turmas do Tribunal Regional Federal da Quarta Região no período de maio de 2005 a agosto de 2010. Das 94 decisões, 48 negaram o direito à saúde, acatando a teoria da reserva do possível, e 46 concederam o medicamento e/ou procedimento postulado, não acolhendo a referida teoria. Ressalta-se que a coleta e a análise dos dados foram realizadas pela aluna Vanessa Reichert, sob orientação do professor Doutor Germano Schwartz, em sede de bolsa PROICT/ULBRA.

${ }^{23}$ Ademais, o SUS disponibiliza e opera com 6,1 mil hospitais credenciados, 45 mil unidades de atenção primária e 30,3 mil equipes de Saúde da Família (ESF). O sistema realiza 2,8 bilhões de procedimentos ambulatoriais anuais, 19 mil transplantes, 236 mil cirurgias cardíacas, 9,7 milhões de procedimentos de quimioterapia e de radioterapia e 11 milhões de internações. Fonte: $<$ http://portal.saude.gov.br/portal/saude/visualizar_texto.cfm?idxt=242627>. Acesso em: 25 out. 2012.
} 
Só o Tribunal de Justiça gaúcho concentra quase a metade das demandas judiciais sobre saúde do país, ou seja, 113.953 ações e no Tribunal Regional Federal da Quarta Região, que compreende os estados do Rio Grande do Sul, Santa Catarina e Paraná, tramitam 8.152 ações $^{24}$. Corroborando para a compreensão do crescimento das demandas judiciais em saúde dentro 0 cenário brasileiro, os dados expostos pelo coordenador do Fórum Nacional do Judiciário para a Saúde, conselheiro Milton Nobre, do CNJ, são importantes para o trabalho em tela:

\begin{abstract}
"Há um exagero descabido no termo 'judicialização da saúde'. Para se ter uma ideia, em 2009 havia cerca de 86 milhões de ações judiciais, das mais diversas naturezas. Conforme pesquisa que ainda está sendo realizada pelo $\mathrm{CNJ}$, as ações relacionadas à saúde não devem chegar nem a 500 mil. Além disso, o Judiciário está fazendo o que deve, defendendo os direitos fundamentais dos cidadãos e cumprindo a Constituição Federal". 25
\end{abstract}

De acordo com Nobre, os números são compatíveis com a realidade de um país de 190 milhões de habitantes, em que 50 milhões têm planos privados de saúde e o restante é atendido exclusivamente pelo SUS. Após a afirmação citada, acrescenta que o recurso à Justiça é o único e derradeiro meio utilizado pelo cidadão que tem dificuldade para ver atendidas suas demandas por atendimento à saúde.

De qualquer forma, em face desse crescimento das demandas judiciais da saúde e a fim de melhor se compreender o entendimento dos Tribunais brasileiros acerca do problema, necessário é o exame da jurisprudência da Corte Especial. Igualmente, indispensável lembrar que o direito à saúde, além de ser garantido constitucionalmente, é também assegurado pelo Direito Federal, como a Lei 8.080 de $1990^{26}$. Nesse contexto, conforme visto anteriormente, uma das funções do Superior Tribunal de Justiça é interpretar e preservar a legislação infraconstitucional uniformizando, por conseguinte, a jurisprudência nacional. Desse modo, como a jurisprudência do Tribunal gaúcho e do Tribunal Regional da Quarta Região já foram analisadas, impõe-se o exame das decisões proferidas pela Corte Superior, a fim de se verificar o seu posicionamento sobre o tema. Ademais, essa pesquisa irá demonstrar se o entendimento dos tribunais já analisados está em consonância com a interpretação dada pelo Tribunal Especial sobre o assunto.

\footnotetext{
${ }^{24}$ Fonte: <http://www.cnj.jus.br/noticias/cnj/14096-brasil-tem-mais-de-240-mil-processos-na-areade-saude> Acesso em: 10 maio 2011.

${ }^{25}$ Presidente do STJ destaca no Fórum da Saúde importância do tema para o Judiciário. Fonte: http://www.stj.gov.br/portal_stj/publicacao/engine.wsp?tmp.area=398\&tmp.texto=99858. Acesso em 18 ago. 2012.

${ }^{26}$ Veja o artigo segundo concomitantemente com o parágrafo primeiro do mesmo artigo da Lei 8.080.
} 


\subsection{Análise dos Dados}

Conforme já referido, foram analisadas oitenta decisões proferidas pelo Superior Tribunal de Justiça no período de 2001 à 2010 que tratavam da escassez de recursos frente ao direito fundamental à saúde. Dessas oitenta decisões, 59 eram originárias do Rio Grande do Sul, isto é, os gaúchos são responsáveis por mais de setenta por cento das demandas da saúde na Corte Superior, conforme demonstra o gráfico abaixo:

\section{ESTADOS DE ORIGEM DAS DECISÕES}

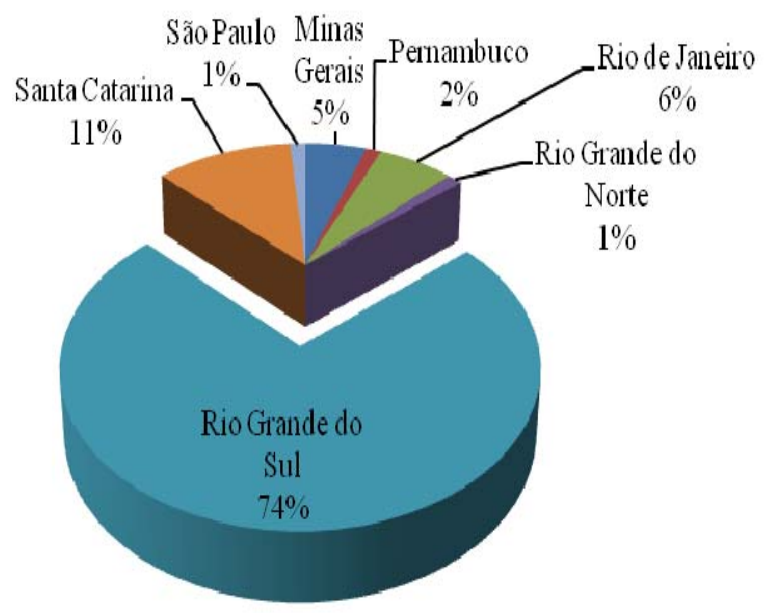

Figura 1 - Gráfico dos Estados de origem das decisões proferidas pela Segunda Turma do Superior Tribunal de Justiça acerca da reserva do possível no direito à saúde.

No que tange à escassez de recursos, dos oitenta julgados examinados, apenas três negaram o direito à saúde em nome da reserva do possível. Importa referir que no Agravo Regimental no Recurso Especial número 1.067.874 originário de São Paulo, e no Agravo Regimental no Recurso Especial número 1.126.936 originário do Rio Grande do Norte os Ministros da Corte Especial entenderam que:

A negativa de fornecimento de um medicamento de uso imprescindível, cuja ausência gera risco à vida ou grave risco à saúde, é ato que, per se, viola a Constituição Federal, pois vida e a saúde são bens jurídicos constitucionalmente tutelados em primeiro plano. A apreciação de supostos preceitos constitucionais não é possível na via especial, nem à guisa de prequestionamento, porquanto matéria reservada, pela Carta Magna, ao Supremo Tribunal Federal. 
Já no Recurso em Mandado de Segurança número 28.338 de Minas Gerais, a Ministra Relatora Eliana Calmon referiu que há precedentes reiterados da Corte Superior reconhecendo, aos portadores de moléstias graves, que não possuam condições financeiras para custear o seu tratamento, o direito de receber gratuitamente do Estado os medicamentos de necessidade comprovada. Contudo, frisou que o dever do Estado de fornecer medicamento não confere ao doente o direito de escolher qualquer fármaco, mas sim aqueles medicamentos constantes nas listas do Sistema Único de Saúde. No caso em tela, o impetrante é portador de moléstia cujo tratamento é fornecido pela rede pública. No entanto, alega o impetrante, em suas razões, que seu médico particular considera ineficaz o medicamento fornecido pelo Estado. Ademais, a Relatora giza que a Administração Pública chegou a oferecer tratamento alternativo, que também fora rejeitado pelo impetrante, muito embora não tenha produzido prova da ineficácia do tratamento fornecido pela Administração. Dessa forma, a Ministra Eliana Calmon negou provimento ao recurso, votando com ela os Ministros Castro Meira, Humberto Martins, Herman Benjamim e Mauro Campbell.

Não obstante, nos setenta e sete julgados que entenderam que o direito fundamental à saúde prevalece frente à reserva do possível foram utilizados vários argumentos a fim de fundamentar tal posicionamento. Giza-se que o argumento mais utilizado foi o de que os direitos fundamentais à vida e à saúde são direitos subjetivos inalienáveis, consagrados constitucionalmente. Nesse sentido, um Estado Democrático de Direito como o brasileiro, que tem como primado a proteção à dignidade da pessoa humana, todas as formas de restrições legais aos direitos fundamentais devem ser superadas. Os Ministros da Corte Especial ainda atentaram para o fato de que, para além do fundamento constitucional, merece destaque que, nas demandas oriundas do Estado do Rio Grande do Sul, deve-se considerar o que dispõe a Lei Estadual número 9.908 de 1993 em seu artigo primeiro:

Art. $1^{\circ}$. O Estado deve fornecer, de forma gratuita, medicamentos excepcionais para pessoas que não puderem prover as despesas com os referidos medicamentos, sem privarem-se dos recursos indispensáveis ao próprio sustento e de sua família.

Parágrafo único. Consideram-se medicamentos excepcionais aqueles que devem ser usados com freqüência e de forma permanente, sendo indispensáveis à vida do paciente.

Ademais, os Ministros do Superior Tribunal de Justiça salientaram que:

A Constituição não é ornamental, não se resume a um museu de princípios, não é meramente um ideário; reclama efetividade real de suas normas. Destarte, na aplicação das normas constitucionais, a exegese deve partir dos princípios fundamentais, para os princípios setoriais. E, sob esse ângulo, merece destaque o princípio fundante da República que destina 
especial proteção a dignidade da pessoa humana. Outrossim, a tutela jurisdicional para ser efetiva deve dar ao lesado resultado prático equivalente ao que obteria se a prestação fosse cumprida voluntariamente. O meio de coerção tem validade quando capaz de subjugar a recalcitrância do devedor. O Poder Judiciário não deve compactuar com o proceder do Estado, que condenado pela urgência da situação a entregar medicamentos imprescindíveis proteção da saúde e da vida de cidadão necessitado, revela-se indiferente à tutela judicial deferida e aos valores fundamentais por ele eclipsados ${ }^{27}$.

Outra questão aventada foi a integralidade do Sistema Único de Saúde SUS. Os julgadores entenderam que, de acordo com esse princípio estabelecido pelo inciso dois do artigo sétimo da Lei 8.080 de 1990, a assistência à saúde, seja individual ou coletiva, deve ser integral. Além disso, deve-se propiciar o atendimento aos que necessitem de assistência, em qualquer grau de complexidade. Dessa maneira, restando comprovado o acometimento do indivíduo ou de um grupo por determinada moléstia, necessitando de determinado medicamento para debelá-la, este deve ser fornecido, de modo a atender ao princípio maior, qual seja a garantia à vida digna. Necessário frisar igualmente que os julgadores da Corte em comento entendem que, muito embora o Supremo Tribunal Federal venha adotando, em algumas hipóteses, a teoria da reserva do possível, o referido Tribunal não tem adotado essa tese no que se refere à preservação dos direitos à vida e à saúde.

Importa referir também que os Ministros entendem ser lícito ao magistrado determinar o bloqueio de valores em contas públicas para garantir o custeio de tratamento médico indispensável. Isso porque, nesses casos, o bloqueio serve como meio de concretizar o princípio da dignidade da pessoa humana e do direito à vida e à saúde. Destarte, nessas situações, a norma contida no artigo 461, parágrafo quinto, do Código de Processo Civil deve ser interpretada em consonância com esses princípios e normas constitucionais, sendo permitida, inclusive, a mitigação da impenhorabilidade dos bens públicos.

Aliás, no que tange à impenhorabilidade dos recursos públicos, o posicionamento majoritário é o de que o direito à saúde se sobrepõe ao referido princípio. Nesse sentido, destaca-se que a grande maioria das decisões faz referência ao voto do Ministro Teori Albino Zavascki, ao julgar o Recurso Especial 840.912, originário do Rio Grande do Sul, que tratava sobre o tema:

Sendo urgente e impostergável a aquisição do medicamento, sob pena de grave comprometimento da saúde da demandante, não teria sentido algum submetê-la ao regime jurídico comum, naturalmente lento, da execução por quantia certa contra a Fazenda Pública. Assim, pode-se

\footnotetext{
${ }^{27}$ BRASIL. Superior Tribunal de Justiça. Agravo Regimental no Agravo de Instrumento $\mathrm{n}^{0}$ 747.806-RS. Agravante: Estado do Rio Grande do Sul. Agravada: Maria Lenir Manarin. Relator: Ministro Herman Benjamim.
} 
ter por legítima, ante a omissão do agente estatal responsável pelo fornecimento do medicamento, a determinação judicial do bloqueio de verbas públicas como meio de efetivação do direito prevalente ${ }^{28}$. (REsp 840.912/RS, Primeira Turma, julgado em 15.02.2007, DJ 23.04.2007)

Com efeito, no que se refere à responsabilidade solidária dos entes da Federação em prestar assistência sanitária, o entendimento majoritário foi o de que a Lei Federal número 8.080 de 1990, com fundamento na Constituição da República, classificam a saúde como um direito de todos e dever do Estado. Por conseguinte, estabelecem um sistema integrado entre todas as pessoas jurídicas de Direito Público Interno, União, Estados e Municípios, responsabilizando-os em solidariedade pelos serviços de saúde, o chamado Sistema Único de saúde - SUS. Desse modo, a divisão de atribuições não pode ser arguida em desfavor do cidadão, pois só tem validade internamente entre eles. Em face disso, a Corte Especial reconhece a legitimidade passiva de quaisquer dos entes federativos no pólo passivo da demanda.

\section{CONSIDERAÇÕES FINAIS}

O exame da jurisprudência do Superior Tribunal de Justiça demonstrou que o entendimento majoritário da referida Corte é o de que o direito fundamental à saúde se sobrepõe à tese da reserva do possível. Isso porque, para os Ministros da Corte Especial, o direito à saúde consiste em uma prerrogativa jurídica indisponível atrelada ao direito à vida e que deve ser garantida a todos. Por conseguinte, conforme os julgados analisados, cumpre ao Poder Público, em todas as suas esferas, organizar-se a fim de assegurar a efetivação do referido direito.

Ademais, verificou-se que a Corte Superior têm cumprido a sua função de interpretar e preservar a legislação infraconstitucional uniformizando, desse modo, a jurisprudência pátria. Nesse sentido imperioso lembrar que, além de garantido constitucionalmente, o direito à saúde também é assegurado pela legislação federal infraconstitucional. Em face disso, o exame da jurisprudência do Superior Tribunal de Justiça demonstrou que as decisões dos Tribunais estaduais que contrariaram ou negaram vigência à Lei 8.080 de 1990 foram modificadas pelos julgadores daquela Corte.

Igualmente merece destaque que, conforme referido ao longo do artigo, essa pesquisa pretende analisar o entendimento jurisprudencial acerca da teoria da reserva do possível no direito à saúde em todas as esferas do Poder Judiciário. Nesse contexto, repisa-se que a análise da jurisprudência da Primeira Câmara Cível do Tribunal de Justiça do Rio Grande do Sul mostrou-se compatível com o entendimento do Superior Tribunal de Justiça. Contudo, parte dos julgados prolatados pela Sétima Câmara Cível do Tribunal gaúcho

\footnotetext{
${ }^{28}$ BRASIL. Superior Tribunal de Justiça. Recurso Especial $n^{\circ} 840.912-R S$. Recorrente: Estado do Rio Grande do Sul. Recorrido: Ministério Público do Rio Grande do Sul. Relator: MinistroTeori Albino Zavascki.
} 
não estão em consonância com a interpretação dada pela Corte superior acerca do tema.

Nesse diapasão, mostra-se pertinente a introdução da repercussão geral no recurso especial, conforme defende Macedo, pena de colapso do Judiciário. A pesquisa que vem sendo realizada pelo Conselho Nacional de Justiça demonstra que os processos atinentes ao direito à saúde versam, em sua maioria, sobre as mesmas questões. Por conseguinte, o óbice recursal defendido por Macedo diminuiria o fluxo dessas demandas, dando mais celeridade aos processos.

\section{REFERÊNCIAS BIBLIOGRÁFICAS}

ABRAMOVICH, Víctor. Linhas de Trabalho em Direitos Econômicos, Sociais e Culturais: instrumentos e aliados. Revista Internacional de Direitos Humanos. Ano 2, no 2, p. 188-223, 2005, Edição em português, Tradução de Maria Lucia de Oliveira Marques.

AMARAL, Gustavo. Direito, Escassez e Escolha: em busca de critérios jurídicos para lidar com a escassez de recursos e as decisões trágicas. Rio de Janeiro: Renovar, 2001. CINTRA, Antônio Carlos de Araújo; GRINOVER, Ada Pellegrini; DINAMARCO, Cândido Rangel. Teoria Geral do Processo. 22. ed., rev. e atual., São Paulo: Malheiros Editores, 2006.

DIDIER JR. Fredie; CUNHA, Leonardo José Carneiro da. Curso de Direito Processual Civil: meios de impugnação às decisões judiciais e processos nos tribunais. v. 3. rev. ampl. e atual. Salvador: Edições Podvim, 2007.

FERREIRA FILHO, Manoel Gonçalves. Direitos Humanos Fundamentais. 9. ed., rev., São Paulo: Saraiva, 2007.

MACEDO, Elaine Harzheim. Os Tribunais Superiores e os Novos Óbices Recursais. In. MACHADO, Fábio Cardoso; MACHADO, Rafael Bicca (Coord.). A Reforma do Poder Judiciário. São Paulo: QuartierLatin, 2006.

MÂNICA, Fernando Borges. Teoria da Reserva do Possível: direitos fundamentais a prestações e a intervenção do Poder Judiciário na implementação de políticas públicas. In: Revista Brasileira de Direito Público. Belo Horizonte, Ano 5, $n^{\circ} 18$, p. 169-186, jul./set. 2007.

MARINONI, Luiz Guilherme; ARENHART, Sérgio Cruz. Curso de Processo Civil: processo de conhecimento. v. 2, 7. ed., rev. e atual., São Paulo: Editora Revista dos Tribunais, 2008.

PINTO, Nelson Luiz. Manual dos Recursos Cíveis. 3. ed., ampl. e atual. São Paulo: Malheiros Editores, 2004.

QUEIROZ, Cristina. Direitos Fundamentais Sociais: funções, âmbito, conteúdo, questões interpretativas e problemas de justiciabilidade. Coimbra: Coimbra Editora, 2006.

SARLET, Ingo. A Eficácia dos Direitos Fundamentais: uma teoria dos direitos fundamentais na perspectiva constitucional. 10. ed., ver. atual. e ampl. Porto Alegre: Livraria do Advogado Ed., 2009.

SILVA, José Afonso da. Curso de Direito Constitucional Positivo. 25. ed., rev. e atual. São Paulo: Malheiros Editores, 2005.

THEODORO JÚNIOR, Humberto. Curso de Direito Processual Civil: teoria geral do direito processual civil e processo de conhecimento. Rio de Janeiro: Forense, 2009. 